\title{
Modulation of neural firing through intracellular ATP dynamics governed by energy feedback from the vascular system
}

\author{
Karishma Chhabria, V Srinivasa Chakravarthy* \\ From 24th Annual Computational Neuroscience Meeting: CNS*2015 \\ Prague, Czech Republic. 18-23 July 2015
}

We propose a simple model for neuro-glio-vascular interactions to emphasize on the role of energy feedback from the vascular system in brain's computations [1,2]. In [1], we introduced a bidirectional communication within a detailed biophysical model of neuron-astrocytevessel. We now compress this model to just two modules: the neuron and the 'energy' module. The energy module is a lumped representation of the astrocytevessel system; it receives neural firing activity as input and controls intracellular neuronal energy (ATPi) levels as a feedback. The model comprises of a quadratic integrate and fire neuron with a dynamic threshold, $V_{t h}$, which further depends on the ATPi dynamics. $V_{t h}$ is high during ATPi deficit, making the neuron least excitable and vice versa for high ATPi conditions. The underlying principle of modeling $V_{t h}$ as a function of
ATPi is based on the experiments describing the role of KATP channels in governing neural excitability [3]. These channels are ATP-dependent potassium channels and are open when ATPi is low, resulting in a depolarized membrane potential of the neuron during metabolically compromised states such as hypoxia [3].

The neuron model parameters are adapted to that of mammalian cortical pyramidal neuron [4]. Furthermore, ATPi dynamics are also modeled similar to [4], where ATPi consumption directly depends on neural spiking activity. The production rate of ATPi, $\varepsilon_{p}$ is a crucial model parameter representing the local vascular activity. A wide range of neural dynamic behaviors: phasic bursting, tonic bursting and continuous spiking are observed by varying $\varepsilon_{p}$ and external input current Iext. Furthermore, simulation of a network consisting of such energy-dependent

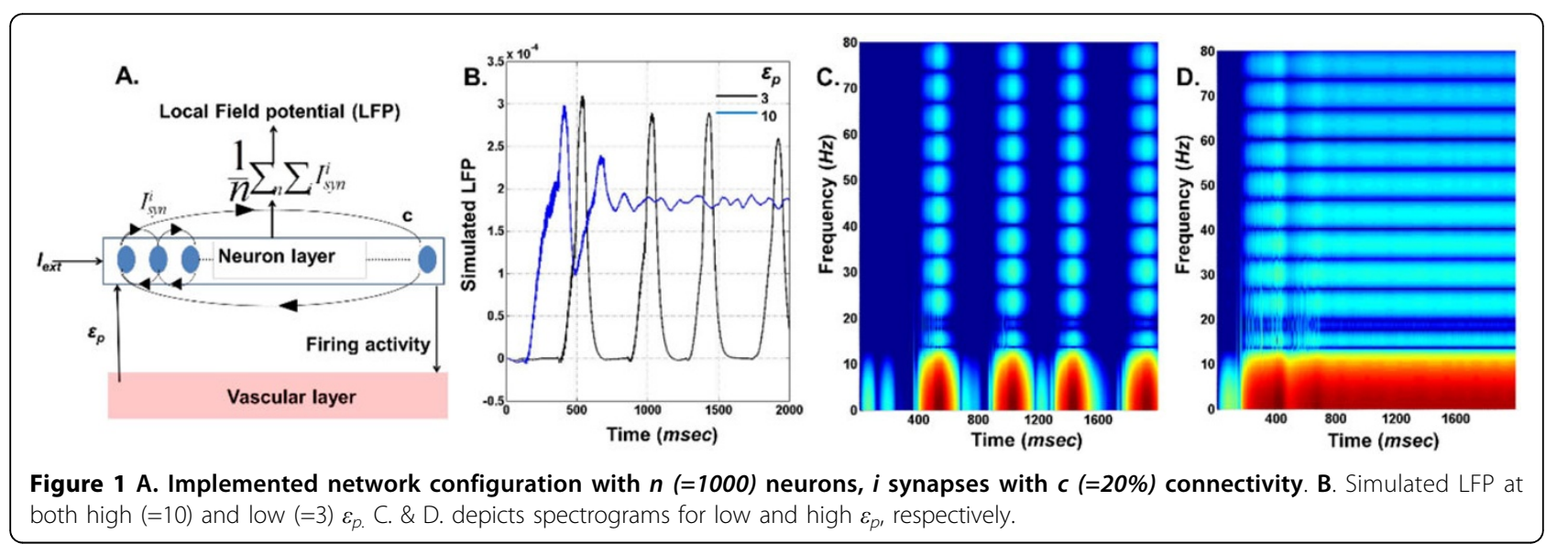

\footnotetext{
* Correspondence: schakra@ee.iitm.ac.in

Department of Biotechnology, Indian Institute of Technology Madras,
} Chennai, 600036, Tamil Nadu, India 
neural units (Figure 1A.) depicts that $\varepsilon_{p}$ could modulate the Local field potential (LFP) frequencies and amplitudes (Figure 1B.). Interestingly, low frequency LFP dominates under low $\varepsilon_{p}$ conditions and could represent seizure-like activity observed in epilepsy. Although conventional neuroscience considers unidirectional influences from neurons to small vessels, there have been proposals that highlight the reverse influence from the vessels to the neurons $[1,2]$. The proposed 'neuron-energy' unit may be treated as a building-block in large scale models of neurovascular networks.

Published: 18 December 2015

\section{References}

1. Chander BS, Chakravarthy VS: A computational model of neuro-gliovascular loop interactions. PloS One 2012, 7(11):e48802.

2. Moore $\mathrm{Cl}$, Cao R: The hemo-neural hypothesis: on the role of blood flow in information processing. Journal of Neurophysiology 2008, 99(5):2035.

3. Wang L, Zhu Q-L, Wang G-Z, Deng T-Z, Chen R, Liu M-H, Wang S-W: The protective roles of mitochondrial ATP-sensitive potassium channels during hypoxia-ischemia-reperfusion in brain. Neuroscience Letters 2011, 491(1):63-67.

4. Ching S, Purdon PL, Vijayan S, Kopell NJ, Brown EN: A neurophysiologicalmetabolic model for burst suppression. Proceedings of the National Academy of Sciences 2012, 109(8):3095-3100.

doi:10.1186/1471-2202-16-S1-P26

Cite this article as: Chhabria and Chakravarthy: Modulation of neural firing through intracellular ATP dynamics governed by energy feedback from the vascular system. BMC Neuroscience 2015 16(Suppl 1):P26.

\section{Submit your next manuscript to BioMed Central} and take full advantage of:

- Convenient online submission

- Thorough peer review

- No space constraints or color figure charges

- Immediate publication on acceptance

- Inclusion in PubMed, CAS, Scopus and Google Scholar

- Research which is freely available for redistribution

Submit your manuscript at www.biomedcentral.com/submit 